\title{
EVALUATION OF THE EFFECT OF VMS IN REDUCING CONGESTION USING AIMSUN TOOL: A CASE STUDY OF ARTERIAL ROAD NETWORKS WITHIN THE CBD OF KADUNA
}

\author{
Aminu Shinkafi Bature', Panagiotis Georgakis ${ }^{2}$ \\ ${ }^{1}$ Department of Small Hydropower, Sokoto Energy Research Centre, Usmanu Danfodiyo University, \\ Sokoto, Nigeria \\ ${ }^{2}$ School of Engineering and the Built Environment, University of Wolverhampton, United Kingdom
}

Received 24 January 2015; accepted 4 April 2016

\begin{abstract}
Microscopic simulation of traffic on the road network within the CBD of Kaduna in Nigeria $\left(10^{\circ} 31^{\prime} 23^{\prime \prime} \mathrm{N}\right.$ and $\left.7^{\circ} 26^{\prime} 25^{\prime \prime} \mathrm{E}\right)$ was carried out using AIMSUN tool to investigate the extent to which variable message signs (VMS) displaying rerouting can improve the perennial congestion without modifying the existing roadways of the city as obtained from the Google Map. Do Nothing Model representing the actual traffic condition on the arterial road networks within the CBD of the city and a VMS Rerouting model representing the behaviour of traffic when VMS displayed rerouting due to congestion were developed.

Traffic state was used to develop the 2 models, using the input and turning flow vehicle demand information. Network and section statistics showing delay time and flow were generated from the models upon completion of animated and batch simulations. The results showed improvement in the network flow of the Do Nothing Model from $7732 \mathrm{veh} / \mathrm{hr}$ to $10699 \mathrm{veh} /$ $\mathrm{hr}$ due to rerouting message conveyed by the VMS representing $38.37 \%$ improvement of the capacity of the network, while the total travel time of the network increase from 208.648 secs/ $\mathrm{km}$ for the Do Nothing Model to $230.001 \mathrm{secs} / \mathrm{km}$ for the VMS Model representing $10.23 \%$.
\end{abstract}

Keywords: microscopic simulation, congestion, variable message sign.

\section{Introduction}

Congestion is a perennial transportation problem globally that results in increase delay and uncertainty in travel time, increase greenhouse gas emissions to the environment, and increase accidents rate. For a city like Kaduna situated in Nigeria $\left(10^{\circ} 31^{\prime} 23^{\prime \prime} \mathrm{N}\right.$ and $\left.7^{\circ} 26^{\prime} 25^{\prime \prime} \mathrm{E}\right)$, continued travel growth, heavy dependent on motorised transport, couple with budgetary constraints for roadway expansion, as well as limit to which new roadway infrastructure can be built due to right of way constraints makes it extremely difficult in ensuring sufficient roadway capacity in the City. Inefficient operation of road networks during period of high traffic demand is the major cause of recurring congestion (Chen et al., 2001). According to ECMT (2007), context-sensitive solutions, such as Variable Message Signs (VMS) are increasingly explored to mitigate the detrimental effects of congestion, while optimizing the use of limited public funding due to high construction costs, constrained right-of-way,

${ }^{1}$ Corresponding author: aminu.bature@udusok.edu.ng 
and environmental factors. VMS are traffic control devices that help manage the network by providing advanced warning to drivers of emergencies and incidents, as well as events that may cause delays in the future such as road works and major events (Highway Agency, 2011). Consequently, this paper investigate the effect of VMS displaying rerouting in improving congestion on the arterial road networks within the Central Business District (CBD) of Kaduna through Microscopic Simulation using AIMSUN tool.

Microscopic simulation enables modelling of highly congested network and solving problems that cannot be solved by analytical methods alone (AIMSUN, 2011). According to Fellendorf (1994), detail evaluation of traffic management measures such as VMS is achieved using micro simulation and because of the stochastic features of traffic, no analytical formulae can be applied to provide such detail information. Thus, Microscopic simulation can contribute to reduce congestion without building new infrastructures because of its ability to provide visual representation of any proposed congestion improvement strategy and measure its effect on traffic operation. According to Clement and Druitt (2006), micro simulation methodology is central to Design Manual for Roads and Bridges (DMRB) and Webtag guidance on scheme appraisal for economic justification of road improvement schemes in the UK.

\section{Method}

Advanced Integrated Microscopic Simulation for Urban Networks (AIMSUN) tool was used to model traffic flow on arterial road networks within the CBD of Kaduna - a city in Northern Nigeria located in the
West of Sub Saharan Africa. Two models were developed using the geometry of the existing road networks as obtained from Google map, for evaluation of congestion on the existing road networks by measuring flow and delay time, as well as study the supposed improvement when VMS rerouting message is conveyed to the Drivers in the model. These models are:

1. Do Nothing Model: This model represent the traffic behaviour on the existing road networks within the $\mathrm{CBD}$ of Kaduna;

2. VMS Displaying Rerouting Model: This model represents the behaviour of traffic on the road networks, when VMS displaying rerouting is introduced into the do nothing model.

\subsection{Traffic State}

Vehicle demand data was added into these models using the traffic state because of the nature of the data obtained which is based on input flow and turning information. The vehicle demand is a data collected from manual classified count that involves counting the number of vehicles that perform each movement at each junction during a particular interval of time and classifying them by vehicle type. This data was used to develop the demand matrix, a profile to that demand and disaggregate demand by vehicle type. Accordingly, for this research, comprehensive sets of traffic count data was obtained at various time intervals for all the arterial roads and intersections located within the CBD of the city and was rationalised to generate traffic state. Specifically, the traffic volume count data obtained on Monday between 07:0009:00AM was used to develop the traffic state for the simulation. Additionally, the 
rationalised data was grouped into input and turning flow and was converted to vehicle per hour before applying it into the model. The data was obtained from the Department of Civil Engineering of Kaduna Polytechnic - Nigeria and Nigerian Institute of Transport Technology Zaria - Nigeria.

\section{Table 1}

Rationalised Traffic Count Data Used as the Input Flow (veh/2hr)

\begin{tabular}{|c|c|c|c|c|}
\hline INPUT FLOW & MOTORCYCLE & CAR & BUS & TRUCK \\
\hline ALI AKILU NORTH & 1268 & 2508 & 968 & 43 \\
\hline ALKALI ROAD EAST & 579 & 765 & 97 & 9 \\
\hline WAFF ROAD W-E (WMC) & 3468 & 3024 & 1480 & 45 \\
\hline SOKOTO ROAD WEST & 2813 & 3199 & 1409 & 3 \\
\hline Y. GOWON WAY W-E & 224 & 960 & 466 & 29 \\
\hline I. TAIWO W-E & 187 & 214 & 193 & 18 \\
\hline KANO ROAD W-E & 186 & 179 & 184 & 18 \\
\hline KATSINA ROAD WEST & 658 & 133 & 275 & 20 \\
\hline KATSINA ROAD EAST & 703 & 110 & 302 & 7 \\
\hline ABUJA ROAD WEST & 602 & 105 & 251 & 3 \\
\hline LAGOS STREET & 478 & 101 & 153 & 21 \\
\hline BARNAWA SOUTH & 369 & 465 & 557 & 35 \\
\hline MOUNTAIN TROOP ROAD & 643 & 1198 & 213 & - \\
\hline GAMJI ROAD E-W & 1084 & 1217 & 317 & - \\
\hline RANCHERS WEST & 975 & 2700 & 2717 & - \\
\hline GOLF COURSE EAST & 2584 & 1498 & 1013 & - \\
\hline OKENE ROAD EAST & 2016 & 2383 & 1995 & - \\
\hline WAFF ROAD & 1712 & 976 & 360 & - \\
\hline ABAKWA WEST & 769 & 1463 & 977 & - \\
\hline BANK ROAD & 476 & 519 & 119 & - \\
\hline
\end{tabular}

However, the rationalised turning flow data is attached as Appendix I.

\subsection{Traffic Management}

Traffic management operation in AIMSUN is supported by strategies and policies. The VMS model is developed using delay and traffic jam policies with turning closure and force rerouting as the measures deployed to check the breakdown of traffic at the Alkali road intersection and Abakwa roundabout.
The warning policy of turning closure of Ali-Akilu (SBL) turning displayed by VMS with $100 \%$ compliance level is activated at 07:20AM. The choice of $100 \%$ compliance for the turning closure is informed by the findings of Erke and Sagberg (2006) that showed that no vehicle drove to the supposedly closed road section when VMS convey a road closure message. At 07:48AM, 
a warning policy displaying delay by VMS is activated with $80 \%$ compliance level at Ali-Akilu (SBR) at Abakwa roundabout.

\section{Presentations of Results}

Animated and batch simulations of the 2 models in AIMSUN were run, as a result of which Section and Network Statistics were generated for each model.

Several variables were obtained from these statistics, however, only flow and delay times were used for this analysis considering their importance in evaluating congestion.

\subsection{Do Nothing Model Result}

The result generated from batch simulation of the Do Nothing Model is presented as network statistics, while that generated from animated simulation is presented as section statistics.

\subsubsection{Network Statistics from the Do Nothing Model}

The data obtained from the network statistics for batch simulation of the Do Nothing Model shows that:

1. The total delay time for the entire network is 136.54 seconds $/ \mathrm{km}$;

2. The delay time for bus is $\mathbf{3 6 2 . 8 2 6}$ seconds/ $\mathrm{km}$ and is the highest delay time for all the vehicle in the network;

3. The truck has the least delay time among all the vehicles in the network with a delay time of 60.2886 seconds $/ \mathrm{km}$;

4. The total flow for the entire network is 7732 vehicle/hr;

5. The car has a flow of 3621 vehicle/hr for the entire network.

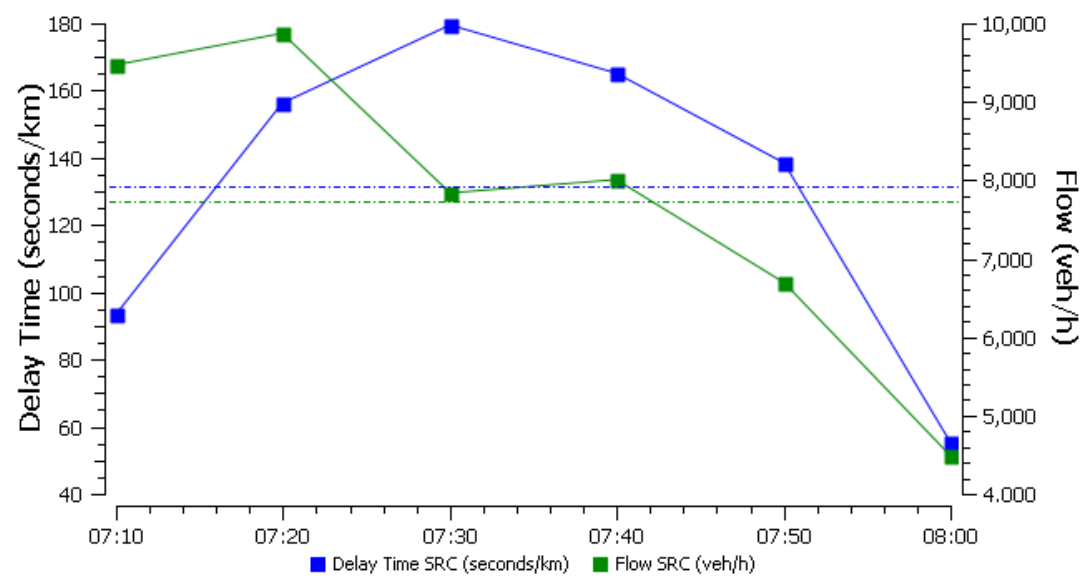

Fig. 1.

Network Total Delay Time and Flow for all Vehicles in the Do Nothing Model against Time 


\subsubsection{Section Statistics from the Do Nothing Model}

Upon replication of animated simulation of the Do Nothing Model, the section statistics was generated for all the intersection leg at Alkali Road junction, NEPA roundabout, Muhammad Buhari Way junction and Golf Course Road intersections.

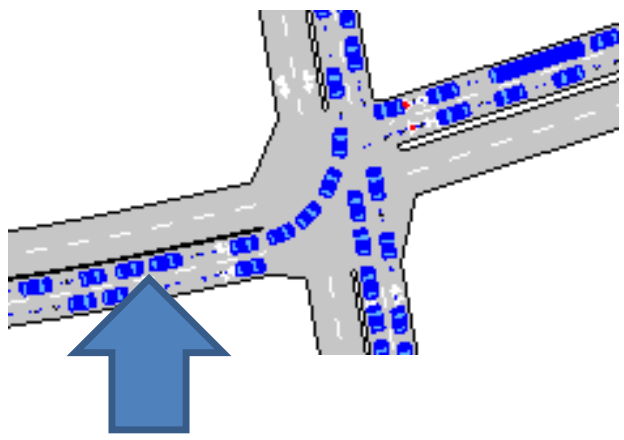

Fig. 2.

Muhammad Buhari Way Junction

Delay time and flow data were obtained for each of the four intersection leg from the time series graph.
The data obtained from the arm of the intersection highlighted by the arrow above showed that:

- The maximum delay time is 2.49 seconds occurring at 07:10AM;

- The mean delay time is 2.22 seconds;

- The maximum flow is 786 vehicle/hr at 07:20AM and the mean flow is 272 vehicle/hr.

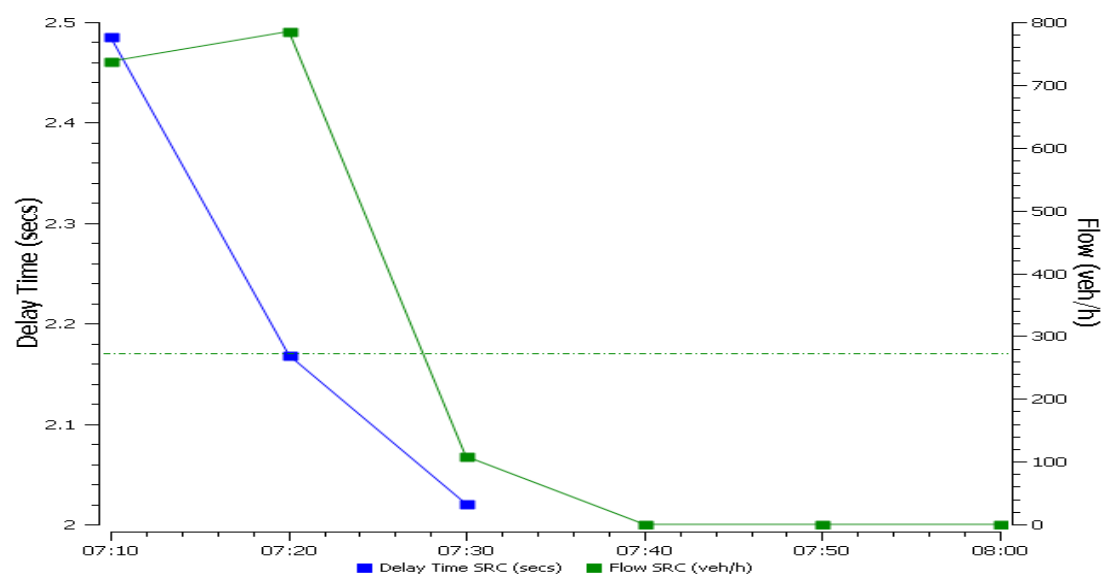

Fig. 3.

Delay Time and Flow for Independence Way North at Muhammad Buhari Way Intersection 


\subsection{VMS Rerouting Display Model}

The network statistics for the VMS rerouting display model is obtained from batch simulation, while the section statistics is obtained upon replication of animated simulation.

\subsubsection{Network Statistics from the VMS Rerouting Display Model}

The data obtained from the network statistics of VMS rerouting display model upon completion of batch simulation shows that:

- The total delay time for the entire network is 158.439 seconds/ $\mathrm{km}$;

- The delay time for bus is 326.838 seconds/ $\mathrm{km}$ representing the highest delay time for all the vehicles in the network;

- The total flow of all vehicles in the network is 10699 vehicle/hr;

- The car has a flow of 5393 vehicle/ $\mathrm{hr}$ representing the highest for all the vehicle in the network.

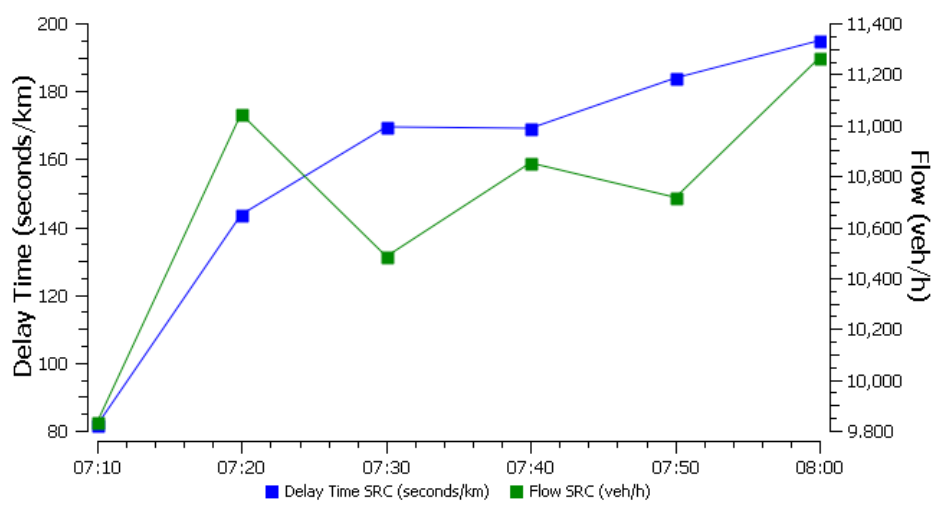

Fig. 4.

Network Delay Time and Flow for all Vehicles in the VMS Rerouting Display Model

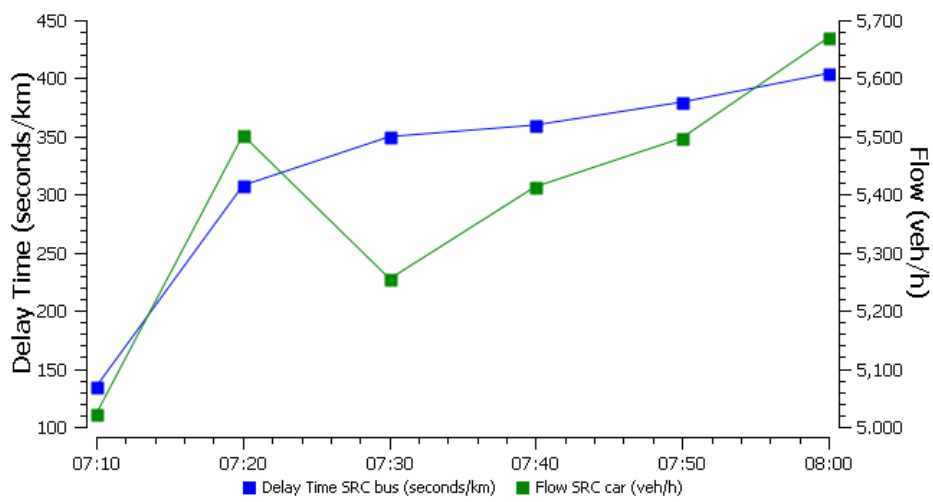

Fig. 5.

Delay Time for Bus and Flow for Car in the Network of VMS Rerouting Display Model 


\subsubsection{Section Statistics from the VMS Rerouting Display Model}

The section statistics of VMS rerouting display model was obtained for the intersection leg at NEPA roundabout and
Alkali road Junction upon replication of animated simulation of the VMS rerouting display model. The data obtained from the time series graph of the four intersection legs of NEPA roundabout is tabulated as follows.

Table 2

Mean and Maximum Delay and Flow Respectively from NEPA Roundabout Intersection

\begin{tabular}{|l|l|l|l|l|}
\hline Intersection Leg & $\begin{array}{l}\text { Maximum } \\
\text { Delay } \\
\text { (Seconds) }\end{array}$ & $\begin{array}{l}\text { Mean Delay } \\
\text { (Seconds) }\end{array}$ & $\begin{array}{l}\text { Maximum Flow } \\
\text { (Vehicle/hr) }\end{array}$ & $\begin{array}{l}\text { Mean Flow } \\
\text { (Vehicle/hr) }\end{array}$ \\
\hline Ahmadu Bello Way North & 80.99 & 66.55 & 1428 & 1116 \\
\hline Waff Road West & 115.55 & 108.14 & 402 & 333 \\
\hline Ahmadu Bello Way South & 7.88 & 5.54 & 462 & 442 \\
\hline Muhammad Buhari Way East & 8.10 & 5.47 & 756 & 676 \\
\hline
\end{tabular}

\section{Discussion of Results}

Delay time and flow parameters obtained from the network and section statistics were used to compare the 2 models because of their relevance to congestion evaluation. These comparisons determine the extent to which VMS as a congestion management measure improve congestion on the existing road networks within the $\mathrm{CBD}$ of the city of Kaduna.

The force rerouting of left turn traffic of Ali-Akilu north and Alkali road east at Alkali road intersection for 30 minutes and 10 minutes respectively with $100 \%$ compliance, and another force rerouting of through traffic of Ali-Akilu road north at Abakwa roundabout for 10 minutes with $80 \%$ compliance which was displayed by the VMS resulted in eliminating the breakdown of traffic flow at Alkali road junction and its spill back that created stand still at the downstream junctions. The total network flow improve from 7732 vehicle/hr to 10699 vehicle/hr due to rerouting message conveyed by the VMS representing $38.37 \%$ improvement in the capacity of the network. However, the total network delay time increase from 136.54 seconds $/ \mathrm{km}$ to 158.439 seconds $/ \mathrm{km}$ when rerouting displayed by VMS is introduced into the Do Nothing Model.

At NEPA roundabout, the mean delay time of Waff road west decrease from 115.09 seconds to 108.14 seconds, while the mean flow increase from 253 vehicle/ $\mathrm{hr}$ to 333 vehicle/hr representing $31.6 \%$ increase in capacity of this intersection leg of the roundabout due to VMS displaying rerouting message. 


\section{Conclusion}

Comparing the flow and delay time generated from the simulation tool due to VMS displaying Rerouting at the 3 strategic intersections with different level of compliance, it can be concluded as follows:

1. VMS displaying Rerouting eliminate breakdown of traffic flow and its spill back on the downstream junctions of road networks;
2. Capacity of the road networks improve by $38.37 \%$ due to VMS conveying Rerouting message;

3. VMS improve the total flow in the road network without modifying the geometry of the road, thereby saving cost associated with road expansion and the impact on the environment;

4. The total road network delay time increase by $16 \%$ due to introduction of VMS conveying rerouting.

\section{Appendix 1}

Traffic Count Data for Selected Intersection within the CBD of Kaduna

\begin{tabular}{|c|c|c|c|c|c|c|c|c|c|c|c|c|c|c|c|c|c|c|c|}
\hline & & & & & & & & kali Road Jur & lunction & 7:00-9:00am & & & & & & & & & \\
\hline Ali Akilu (S-N) & $\begin{array}{l}\text { Motor } \\
\text { cycle }\end{array}$ & Car & Bus & Truck & Ali Akilu (N-S) & $\begin{array}{l}\text { Motor } \\
\text { cycle }\end{array}$ & Car & Bus & Truck & Alkali East & \begin{tabular}{|l|}
$\begin{array}{l}\text { Motorc } \\
\text { ycle }\end{array}$ \\
\end{tabular} & $\mathrm{Car}$ & Bus & Truck & & & & & \\
\hline $\begin{array}{l}\text { Turn Right S-E } \\
\text { (Alkali) }\end{array}$ & 447 & 427 & 35 & & $\begin{array}{l}\text { Turn Left N-E } \\
\text { (Akkali) }\end{array}$ & 177 & 378 & 19 & & \begin{tabular}{l|l} 
& $\begin{array}{l}\text { Turn Right E-N } \\
\text { (Ali Akilu }\end{array}$ \\
7 & North) \\
\end{tabular} & 189 & 355 & 16 & & & & & & \\
\hline $\begin{array}{l}\text { Straight S-N (Ali } \\
\text { Akilu) }\end{array}$ & 1548 & 2068 & 1054 & & $\begin{array}{l}\text { Straight N-S (Ali } \\
\text { Akilu) }\end{array}$ & 1091 & 2130 & 949 & & $\begin{array}{l}36 \text { Turr leff E-S } \\
\text { (Ali Akilu Suth) }\end{array}$ & 390 & 410 & 81 & 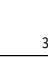 & & & & & \\
\hline & & & & & & & & EPA Rounda & dabout 7 & 7:00 -9:00am & & & & & & & & & \\
\hline $\begin{array}{l}\text { A. Bello Way S- } \\
\text { N }\end{array}$ & $\begin{array}{l}\text { Motor } \\
\text { cycle }\end{array}$ & Car & Bus & Truck & A. Bello Way N-S & $\begin{array}{l}\text { Motor } \\
\text { cycle }\end{array}$ & Car & Bus & Truck & $\begin{array}{l}\begin{array}{l}\text { Waff Road E- } \\
\text { W }\end{array} \\
\end{array}$ & \begin{tabular}{|l|}
$\begin{array}{l}\text { Motorc } \\
\text { ycle }\end{array}$ \\
\end{tabular} & $\mathrm{Car}$ & Bus & Truck & $\begin{array}{l}\text { Waff Road W- } \\
\text { E }\end{array}$ & \begin{tabular}{|l|}
$\begin{array}{l}\text { Motorcy } \\
\text { cle }\end{array}$ \\
\end{tabular} & Car & Bus & Truck \\
\hline $\begin{array}{l}\text { Turn RightS-E } \\
\text { (Waff Road) }\end{array}$ & 1750 & 505 & 739 & & $\begin{array}{l}\text { Turn Right N-W } \\
\text { (Wafff West) }\end{array}$ & 473 & 68 & 272 & & $\begin{array}{l}\text { Turn Right E-N } \\
\text { (AB Way } \\
8 \text { North) }\end{array}$ & 1253 & 1263 & 478 & & $\begin{array}{l}\text { Turn Right W- } \\
\text { S (AB Way } \\
\text { South) }\end{array}$ & 2428 & 2117 & 1036 & 32 \\
\hline $\begin{array}{l}\text { Straight S-N (AB } \\
\text { way North) }\end{array}$ & 750 & 217 & 317 & & $\begin{array}{l}\text { Straight N-S (AB } \\
4 \text { way South) }\end{array}$ & 1103 & 157 & 634 & & 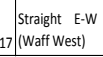 & 1880 & 1895 & 718 & & $\begin{array}{l}\text { Straight W-E } \\
\text { (Hamdala) }\end{array}$ & 1040 & 907 & 444 & 13 \\
\hline & & & & & & & & koto Road J & IJunctior & on 7:00-9:00am & & & & & & & & & \\
\hline $\begin{array}{l}\text { A Bello Way N- } \\
S\end{array}$ & $\begin{array}{l}\text { Motor } \\
\text { cycle }\end{array}$ & Car & Bus & Truck & \begin{tabular}{|l} 
Sokoto Road \\
(West)
\end{tabular} & \begin{tabular}{|l} 
Motor \\
cycle
\end{tabular} & Car & Bus & Truck & & & & & & & & & & \\
\hline $\begin{array}{l}\text { Turn Right N-W } \\
\text { (Sokoto Road) }\end{array}$ & 1859 & 2335 & 588 & & $\begin{array}{l}\text { Turn right W-S (AB } \\
\text { Way South) }\end{array}$ & 2813 & 3199 & 1409 & & 3 & & & & & & & & & \\
\hline $\begin{array}{l}\text { Straight N-S (AB } \\
\text { Waysouth) }\end{array}$ & 2789 & 3202 & 883 & & 7 & & & & & & & & & & & & & & \\
\hline & & & & & & & & ventis Roun & Indabout & ut 7:00-9:00am & & & & & & & & & \\
\hline AB Way N-S & $\begin{array}{l}\text { Motor } \\
\text { cycle }\end{array}$ & Car & Bus & Truck & AB Way S-N & $\begin{array}{l}\text { Motor } \\
\text { cycle }\end{array}$ & Car & Bus & Truck & YG way E-W & \begin{tabular}{|l|} 
Motorc \\
ycle
\end{tabular} & Car & Bus & Truck & YG Way W-E & \begin{tabular}{l|}
$\begin{array}{l}\text { Motorcy } \\
\text { cle }\end{array}$ \\
\end{tabular} & Car & Bus & Truck \\
\hline $\begin{array}{l}\text { Turn Right N-W } \\
\text { (Chechenya } \\
\text { Road) }\end{array}$ & 210 & 192 & 404 & & 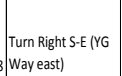 & 403 & 750 & 209 & & \begin{tabular}{l|l} 
Turn Right E-N \\
(AB Way \\
North)
\end{tabular} & 203 & 636 & 261 & & \begin{tabular}{|l} 
Turn Right W- \\
S (AB Way \\
South)
\end{tabular} & 146 & 624 & 303 & 19 \\
\hline $\begin{array}{l}\text { Straight N-S (AB } \\
\text { Way South) }\end{array}$ & 210 & 193 & 404 & & $\begin{array}{l}\text { Straight S-N (AB } \\
\text { Way North) }\end{array}$ & 413 & 750 & 209 & & $\begin{array}{l}222 \text { Road) } \\
\text { (Craight E-W } \\
\text { Rechenya }\end{array}$ & 203 & 635 & 266 & & \begin{tabular}{|c} 
Straight W-E \\
$($ (YG Way East)
\end{tabular} & 78 & 336 & 163 & 10 \\
\hline
\end{tabular}




\section{References}

AIMSUN. 2011. Introduction to Micro Simulation. Available from Internet: <http://www.microsimulation. drfox.org.uk/intro.html>.

Chen, C.; Jia, Z.; Varaiya, P. 2001. Causes and cures of highway congestion. Available from Internet: <http:// iew3.technion.ac.il/serveng/Lectures/causes_curves_ highway.pdf $>$.

Clement, L.; Druitt, S. 2006. How microsimulation unlocks the economic benefits of road improvement schemes. Available from Internet: <http://www.sias. com/ng/sparticles/pdfs/TEC/Appraisal.pdf $>$.
Erke, E.; Sagberg, F. 2006. Effects of variable message signs (vms) on driver attention and behaviour. Association for European Transport and Contributor 2006. Institute of Transport Economics.

European Conference of Ministers of Transport. 2007. Managing Urban Traffic Congestion, Paris.

Fellendorf, I.M. 1994. VISSIM: A microscopic simulation tool to evaluate actuated signal control including bus priority. $64^{\text {th }}$ Annual meeting. Dallas.

Highways Agency. 2011. Variable Message Signs. Available from Internet: <http://www.highways.gov. uk/knowledge/334.aspx $>$. 